\title{
FATORES QUE CONTRIBUEM PARA O INÍCIO DA ATIVIDADE SEXUAL EM ADOLESCENTES: REVISÃO INTEGRATIVA
}

\author{
FACTORS THAT CONTRIBUTE TO THE ONSET OF SEXUAL \\ ACTIVITY IN ADOLESCENTS: INTEGRATIVE REVIEW
}

\section{Taciana Mirella Batista dos Santos ${ }^{a^{*}}$, Lívia Brito Bezerra de Albuquerque ${ }^{b^{*}}$, Carolina da Franca Bandeira ${ }^{\mathrm{c}^{*}}$, Viviane Soares de Andrade Colares ${ }^{\mathrm{d}^{*}}$ \\ atacianamirella@hotmail.com, blivia_brito_@hotmail.com, 'carolina.franca@upe.br, dviviane.colares@upe.br *Universidade de Pernambuco - Recife (PE), Brasil}

\section{RESUMO}

Introduçáo: A atividade sexual tem acontecido frequentemente durante a adolescência. Os adolescentes que iniciam essa atividade muito cedo estão expostos a riscos relacionados à atividade sexual desprotegida, que pode ter como consequência o aumento do risco de infecção sexualmente transmissível, gravidez precoce, evasão escolar, entre outras. Este estudo tem como objetivo identificar os fatores associados ao início da atividade sexual de adolescentes. Desenvolvimento: Trata-se de uma revisão integrativa da literatura que analisou 11 artigos dos 717 encontrados na Biblioteca Virtual de Saúde. Foram incluídos estudos realizados com adolescentes brasileiros publicados entre os anos de 2003 e 2013. Nesta revisão, a sexarca esteve associada a múltiplos fatores. Os mais citados foram idade, gênero e questóes culturais, influência dos pares, religião, família, relaçóes de namoro, escolaridade e fator socioeconômico. Conclusão: A existência de fatores intrínsecos e extrínsecos influencia o comportamento sexual, devendo ser discutida, especialmente, antes do início da prática sexual.

Palavras-chave: Comportamento sexual; educação sexual; saúde sexual; sexismo; sexualidade.

\section{ABSTRACT}

Introduction: Sexual activity has often happened during adolescence. Adolescents who start this activity too early are exposed to risks related to unprotected sexual activity, which can have as consequence an increasing risk of sexually transmitted infections, teen pregnancy, school dropouts, among others. This study aims to identify factors associated with early sexual activity among adolescents. Development: This is an integrative literature review, which have analyzed 11 of the 717 articles found in the Virtual Health Library. Studies performed with Brazilian adolescents, published between 2003 and 2013 were included. In this review the first sexual intercourse was associated with multiple factors. The most frequently cited were age, gender and cultural issues, peer influence, religion, family, dating relationships, education and socioeconomic factor. Conclusion: The existence of intrinsic and extrinsic factors influence the sexual behavior and should be discussed, especially before the onset of sexual practices.

Keywords: Sexual behavior; sexual education; sexual health; sexism; sexuality. 


\section{Introdução}

É na adolescência que ocorre a formação da identidade dos indivíduos, como resultado de modificaçôes biológicas e sociais enfrentadas por eles. É justamente pela diversidade de conflitos, do conjunto de experiências e influências de crenças e valores que os adolescentes são considerados vulneráveis. Esses indivíduos vivenciam, nessa fase da vida, mudanças físicas, hormonais, emocionais, sociais e sexuais, que ocorrem de forma simultânea. Devido à complexidade do processo de formação do ser humano tem-se a adolescência como um período de vulnerabilidade ${ }^{1,2}$.

Para a Organização Mundial de Saúde (OMS) esse período é classificado em fases distintas, sendo a pré-adolescência idade entre 10 e 14 anos, e a adolescência dos 15 aos 19 anos. Essa classificaçáo facilita o estudo de cada grupo e permite a identificação dos fatores de vulnerabilidade que se expóe em cada fase ${ }^{3}$. As mudanças biológicas desta fase são marcadas por acelerada maturação sexual, definida como puberdade, que tem como características o crescimento do corpo, a assemelhação ao corpo adulto, novas formas físicas ${ }^{2}$. Dentro desse contexto pode acontecer a primeira relação sexual, que para os adolescentes é o principal acontecimento que marca a mudança para a vida adulta ${ }^{4}$.

Uma das consequências da atividade sexual na adolescência pode ser a gravidez precoce e náo programada e principalmente as repercussóes que podem causar na vida desses adolescentes. Em meio a tantas mudanças, a gestaçáo nesse momento pode alterar a percepçáo que as jovens têm de si, afetando a autoimagem e a autoestima. Segundo a literatura, uma das consequências da gestação na adolescência é a evasão escolar5. Além disso, para essas jovens, as possibilidades de inserção no mercado de trabalho são menores, assim como as chances de melhores condiçóes financeiras a elas e ao filho5.

De maneira geral, homens e mulheres apresentam comportamento sexual diferente, e são motivados a iniciar da atividade sexual (sexarca) por fatores diferentes ${ }^{6}$. No entanto, a literatura tem mostrado que a idade de início da prática sexual tem diminuído para ambos ${ }^{5,7,8}$. No Brasil, embora a média de idade da sexarca venha declinando em ambos os sexos, os rapazes iniciam a prática sexual com menos idade que as garotas. Na década de 1950, a sexarca apresentava-se por volta dos 20,5 anos; em 1975, aos 18,6 anos; em 1996, aos 16,4 anos. Um estudo realizado entre os anos de 1998 a 2004-5 revelou que a idade média da primeira relação sexual de jovens foi de 15 anos entre os homens e de 15,9 anos entre as mulheres ${ }^{4}$.

Por ser a adolescência um período considerado de risco epidemiológico para infecçâo sexualmente transmissível (IST), gravidez precoce, evasão escolar, entre outras consequências ${ }^{8}$, vê-se a importância de conhecer os fatores que postergam e os que promovem a sexarca a fim de planejar melhor as orientaçôes e as açóes direcionadas a esse grupo.
Além disso, dispor de tais informaçóes se faz necessário para a sociedade de modo geral, especialmente para pais, educadores e profissionais de saúde, pois o início precoce dessa prática pode apresentar impacto na saúde pública, e as consequências podem repercutir na família, no indivíduo e na sociedade. Conhecer como se dá o início da atividade sexual é essencial para quem lida com adolescentes, porque fornece subsídios para compreender e ajudar na adaptação e enfrentamento das dificuldades próprias da adolescência.

Partindo dessa discussão, esse estudo tem como objetivo identificar os fatores associados ao início da atividade sexual em adolescentes.

\section{Desenvolvimento}

Trata-se de uma revisão bibliográfica e sistematizada, cuja trajetória metodológica percorrida apoia-se na leitura exploratória e seletiva do material de pesquisa, contribuindo para o processo de síntese e análise dos resultados de vários estudos.

As etapas que conduziram essa revisão foram: identificação do tema; formulação de uma questáo norteadora; estabelecimento de critérios para a inclusão e exclusão dos artigos selecionados; definição das características das pesquisas primárias que compóem essa revisão da literatura; avaliação dos artigos incluídos; interpretação dos resultados e apresentação da revisão, proporcionando exame crítico dos achados.

O estudo foi desenvolvido com base na seguinte questão norteadora: "Quais fatores estão associados ao início da prática sexual entre os adolescentes?".

Foram selecionados os artigos que obedeceram aos seguintes critérios de inclusão: o período de publicação entre 2003 e 2013; ser redigido nos idiomas: inglês, espanhol e português; investigar fatores associados ao início da prática sexual em adolescentes brasileiros.

A busca incluiu artigos indexados nas bases de dados da Biblioteca Virtual em Saúde (BIREME) entre elas: Literatura Latino-Americana de Ciências da Saúde (Lilacs), Medical Literature Analysis and Retrieval System on Line (Medline) e Scientific Eletronic Library Online (Scielo). Utilizou-se a seguinte estratégia de busca: cruzamento das palavras chave "iniciaçáo sexual" e "sexarca" com os descritores "adolescente", "comportamento do adolescente", "saúde do adolescente" e "comportamento sexual". Os resultados dessa busca somaram 717 publicaçóes; após a aplicação dos critérios de exclusão, foram eliminados 653 , incluindo trabalhos de revisão de literatura. Nesta etapa ficaram 64 artigos. Depois, mais trinta foram excluídos após a leitura dos títulos e resumos, restando 34 artigos. Em seguida, foram eliminados 23 artigos, pois encontravam-se duplicados e indexados em mais de uma base. Portanto, 11 artigos compuseram a amostra. (Tabela 1). 
Tabela 1: Distribuição das associações utilizadas para busca das referências

\begin{tabular}{lcclc}
\hline $\begin{array}{l}\text { Combinaçáo dos } \\
\text { descritores }\end{array}$ & Resultados da busca & $\begin{array}{c}\text { Resultados da busca } \\
\text { com filtros }\end{array}$ & $\begin{array}{l}\text { Após leitura de título } \\
\text { e resumo }\end{array}$ & $\begin{array}{c}\text { Após } \\
\text { exclusão dos artigos } \\
\text { duplicados }\end{array}$ \\
\hline $\begin{array}{l}\text { [Educaçáo em saúde] and } \\
\text { [Sexualidade] and [Adolescente] }\end{array}$ & 379 & 12 & 01 LILACS & 01 \\
[Iniciaçáo sexual] and \\
$\begin{array}{l}\text { comportamento] } \\
\text { [Iniciação sexual] and [Educação] }\end{array}$
\end{tabular}

Quadro 1: Artigos selecionados

\begin{tabular}{|c|c|c|c|c|}
\hline Autor/Ano & Amostra & Delineamento de pesquisa & Sexarca(anos) & Resultados \\
\hline $\begin{array}{l}\text { Leite et al. }{ }^{10} \\
(2004)\end{array}$ & $\begin{array}{l}\mathrm{n}=3.035 \\
\text { mulheres; } \\
15 \text { e } 24 \text { anos; }\end{array}$ & $\begin{array}{l}\text { Epidemiológico. } \\
\text { Dados provenientes da Pesquisa } \\
\text { Nacional Sobre Demografia e Saúde } \\
\text { de } 1996 .\end{array}$ & $\begin{array}{l}\text { Início: } \\
13 \text { a } 17 \text { anos. }\end{array}$ & $\begin{array}{l}\text { Fatores preditores para iniciação sexual: } \\
\text { - idade entre } 13 \text { e } 17 \text { anos; } \\
\text { - jovens da área urbana. } \\
\text { - menor nível de escolaridade; } \\
\text { - influência da comunidade; } \\
\text { - a religião foi um fator que protelou a } \\
\text { sexarca; }\end{array}$ \\
\hline $\begin{array}{l}\text { Borges }^{11} \\
(2007)\end{array}$ & $\begin{array}{l}\mathrm{n}=335 \\
\text { adolescentes } \\
\text { de } 15 \text { a } 19 \\
\text { anos; }\end{array}$ & $\begin{array}{l}\text { Transversal. } \\
\text { Questionário } \\
\text { (zona oeste do Município } \\
\text { de São Paulo). }\end{array}$ & $\begin{array}{l}\text { Média: } 16,8 \\
\text { anos. }\end{array}$ & $\begin{array}{l}\text { Fatores preditores para iniciação sexual: } \\
\text { - pressão dos pares (principalmente entre os } \\
\text { garotos); } \\
\text { - ter amigo que já iniciou atividade sexual; } \\
\text { - idade; } \\
\text { - relação anterior de namoro/ "ficar"; }\end{array}$ \\
\hline $\begin{array}{l}\text { Borges et al. }{ }^{12} \\
(2007)\end{array}$ & $\begin{array}{l}\mathrm{n}=383 \\
\text { adolescentes } \\
\text { solteiros entre } \\
15 \text { e } 19 \text { anos } \\
\text { de idade; }\end{array}$ & $\begin{array}{l}\text { Transversal. } \\
\text { Entrevista } \\
\text { (zona leste do Município } \\
\text { de São Paulo). }\end{array}$ & $\begin{array}{l}\text { Mulheres } 15 \\
\text { a } 17 . \\
\text { Homens } 15 \text { a } \\
17 \text { anos. }\end{array}$ & $\begin{array}{l}\text { Fatores preditores para iniciação sexual: } \\
\text { - ausência do sistema educacional; } \\
\text { - ter namorado anteriormente; } \\
\text { - ter uma irmá/irmáo que passou por uma } \\
\text { gestaçáo fora de uma união conjugal; } \\
\text { - escolaridade dos pais; } \\
\text { - estar trabalhando; } \\
\text { - não rigidez dos pais (os garotos); }\end{array}$ \\
\hline $\begin{array}{l}\text { Pelloso et al. }{ }^{13} \\
(2008)\end{array}$ & $\begin{array}{l}\mathrm{n}=80 \\
\text { adolescentes, } \\
\text { de } 12 \text { a } 19 \\
\text { anos; }\end{array}$ & $\begin{array}{l}\text { Descritivo exploratório. } \\
\text { Questionário. }\end{array}$ & $\begin{array}{l}\text { Mulheres } 15 \\
\text { a } 17 . \text { Homens } \\
11 \text { a } 16 .\end{array}$ & $\begin{array}{l}\text { Fatores preditores para iniciação sexual: } \\
\text { - os homens mostraram-se mais livres para os } \\
\text { relacionamentos; } \\
\text { - Motivos para não iniciar a atividade } \\
\text { sexual:meninas tinham medo de perder a } \\
\text { virgindade por motivos pessoais, afetivos e } \\
\text { sociais; }\end{array}$ \\
\hline $\begin{array}{l}\text { Paiva et al. }{ }^{8} \\
(2008)\end{array}$ & $\begin{array}{l}\mathrm{n}=670 \\
16 \text { a } 19 \text { anos } \\
\text { sexualmente } \\
\text { ativos; }\end{array}$ & $\begin{array}{l}\text { Transversal.Entrevista por duas pes- } \\
\text { quisas, realizadas em } 1998 \text { e } 2005 \text {. }\end{array}$ & Média:14,9. & $\begin{array}{l}\text { Fatores preditores para iniciação sexual: } \\
\text { - permanecem as diferenças entre rapazes e } \\
\text { moças, a idade na primeira relação sexual é } \\
\text { menor entre os rapazes;não ter religião; } \\
\text { - menor renda familiar; } \\
\text { - menor escolaridade }\end{array}$ \\
\hline $\begin{array}{l}\text { Gubert e } \\
\text { Madureira }^{14} \\
\text { (2008) }\end{array}$ & $\begin{array}{l}340 \\
\text { adolescentes } \\
\text { do sexo } \\
\text { masculino } \\
\text { entre } 14 \text { e } 19 \\
\text { anos; }\end{array}$ & $\begin{array}{l}\text { Quantitativa. } \\
\text { Questionário(Concórdia, Santa } \\
\text { Catarina). }\end{array}$ & $\begin{array}{l}\text { Início: } \\
13 \text { anos } \\
\text { Média: } \\
14,4 \text { anos }\end{array}$ & $\begin{array}{l}\text { Fatores preditores para iniciação sexual: } \\
\text { - desejo/ vontade; } \\
\text { • idade; } \\
\text { • ser homem, provar a masculinidade; } \\
\text { - a maioria iniciou a atividade sexual com } \\
\text { "ficantes"; }\end{array}$ \\
\hline
\end{tabular}

continua... 
Quadro 1: Continuação

\begin{tabular}{|c|c|c|c|c|}
\hline Autor/Ano & Amostra & Delineamento de pesquisa & Sexarca(anos) & Resultados \\
\hline $\begin{array}{l}\text { Cruzeiro et } \\
\text { al. }{ }^{15}(2008)\end{array}$ & $\begin{array}{l}\mathrm{n}=960 \\
\text { adolescentes } \\
\text { de } 15 \text { a } 18 \\
\text { anos; }\end{array}$ & $\begin{array}{l}\text { Transversal. } \\
\text { Questionário(Pelotas, RS). }\end{array}$ & $\begin{array}{l}\text { Mediana: } \\
16,7\end{array}$ & $\begin{array}{l}\text { Fatores preditores para iniciação sexual: } \\
\text { - os meninos iniciaram precocemente.uso de } \\
\text { tabaco, álcool e portar arma nos últimos } 12 \\
\text { meses; } \\
\text { - Motivos para não iniciar a atividade sexual:- } \\
\text { morar com a mãe ou com o pai; } \\
\text { - estar empregado; } \\
\text { - Possuir religião. }\end{array}$ \\
\hline $\begin{array}{l}\text { Gonçalves et } \\
\text { al. }^{4}(2008)\end{array}$ & $\begin{array}{l}\mathrm{n}=4297 \\
\text { jovens de } 23 \\
\text { anos; }\end{array}$ & $\begin{array}{l}\text { Estudo de coorte iniciado em } 1982 \text { e } \\
\text { reavaliado em 2004-2005. (Pelotas, } \\
\text { RS) }\end{array}$ & $\begin{array}{l}\text { Início a partir } \\
\text { de } 12 \text { anos } \\
\text { Média: } \\
\text { Mulheres } 17 \text { e } \\
\text { Homens } \\
\text { 14anos }\end{array}$ & $\begin{array}{l}\text { Fatores preditores para iniciaçáo sexual: } \\
\text { - renda familiar baixa; } \\
\text { • menor escolaridade.ser homem, provar a } \\
\text { masculinidade; }\end{array}$ \\
\hline $\begin{array}{l}\text { Bergamim } \\
\text { e Borges }^{6} \\
(2009)\end{array}$ & $\begin{array}{l}\mathrm{n}=335 \\
\text { adolescentes } \\
\text { entre } 15 \text { e } 19 \\
\text { anos; }\end{array}$ & $\begin{array}{l}\text { Transversal } \\
\text { Quantitativo } \\
\text { Questionário } \\
\text { (zona oeste do município de São } \\
\text { Paulo) }\end{array}$ & Média: 14,8 & $\begin{array}{l}\text { Fatores preditores para iniciação sexual: } \\
\text { - não houve diferenças nas idades de inicia- } \\
\text { ção sexual entre homens e mulheres; } \\
\text { - não estudar e ter baixo nível de } \\
\text { escolaridade; } \\
\text { - morar com apenas um dos pais; } \\
\text { - os pais concordarem (ambos os sexos); } \\
\text { - ter amigo que já iniciou atividade sexual; } \\
\text { - estar namorando. }\end{array}$ \\
\hline $\begin{array}{l}\text { Hugo et al. }{ }^{16} \\
(2011)\end{array}$ & $\begin{array}{l}\mathrm{n}=1468 \\
\text { jovens de } 18 \text { a } \\
24 \text { anos; }\end{array}$ & $\begin{array}{l}\text { Transversal Quantitativo Questionário } \\
\text { (zona urbana da cidade de Pelotas) }\end{array}$ & $\begin{array}{l}\text { Média: } \\
15,7\end{array}$ & $\begin{array}{l}\text { Fatores preditores para iniciação sexual: } \\
\text { - menor escolaridade; } \\
\text { - ser homem; } \\
\text { - ter pais separados; } \\
\text { - náo praticar a religiáo;uso de drogas e fumo } \\
\text { nos últimos três meses. }\end{array}$ \\
\hline
\end{tabular}

Foi realizada a revisão por pares como forma de minimizar a subjetividade na seleção dos artigos. A leitura minuciosa dos onze artigos possibilitou extrair as seguintes informaçóes: autores, ano de publicação, periódico de publicação, tipo de estudo, objetivos, características da amostra, metodologia, resultados. Os resultados estão apresentados no Quadro 1.

\section{O início da atividade sexual em adolescentes}

As pesquisas no Brasil apontam que o início da prática sexual ocorre na adolescência. A prática sexual para meninos e meninas, de maneira geral, tem ocorrido entre 14 e 17 anos $^{6,9,11,12,14}$, especialmente após os 17 anos, idade aproximada para quando a virgindade parece pesar para ambos, embora os homens sintam-se mais pressionados pelos pares e o evento ganha maior dimensão?. É uma espécie de ritual, um código de conduta, com a intenção de provar a masculinidade 9 . Os adolescentes do sexo masculino têm iniciado essa atividade mais cedo do que as do sexo feminino $9,12,13,14,15,16$, e segundo a literatura iniciar a atividade sexual precocemente está relacionado ao menor uso do preservativo ${ }^{17}$, fato que deixa esses adolescentes em maior vulnerabilidade ${ }^{14,15}$.

Embora os artigos selecionados não conceituem atividade sexual precoce, foi encontrado esse termo ao se referir a adolescentes que iniciaram a sexarca com idade menor ou igual a $13 \operatorname{anos}^{4}$. Um dos $\operatorname{artigos}^{8}$, embora não tenha usado o termo precoce, constatou que alguns garotos iniciaram a atividade sexual aos 14 anos, outro aos $11 \operatorname{anos}^{14}$.

\section{Diferenças de gêneros na iniciação da atividade sexual}

Todos os artigos mencionaram a diferença de gêneros, reafirmando que ainda hoje homens e mulheres enfrentam a virgindade e a primeira relação sexual de maneira distinta. Entre alguns adolescentes o afeto foi 
valorizado, e um estudo com abordagem quantitativa realizado na zona leste de São Paulo mostrou que 31\% dos meninos ${ }^{9}$ preferem experimentar a atividade sexual quando estão envolvidos em alguma relação afetivo-amorosa. Outro estudo realizado no Paraná ${ }^{13}$ demonstra que as meninas disseram ser necessário um envolvimento emocional para iniciar a prática sexual. Em estudo quantitativo realizado na zona leste de São Paulo com adolescentes de idade entre 15 e 19 anos encontrou-se que $76,4 \%$ das meninas concordam que "a mulher deve se guardar para alguém especial”, acreditam que o sexo deve acontecer com uma pessoa a qual se tenha alguma ligação sentimental ${ }^{6}$.

O principal motivo para os adolescentes do sexo masculino foi sentir-se atraído fisicamente ${ }^{9,14}$. Embora alguns garotos, na sua minoria, mencionaram estar à espera da "pessoa certa", por isso preferiam manter-se virgens $^{9,14}$, a maioria afirmou que a relação afetiva com a parceira não importa ${ }^{13,14}$, que estáo à espera da primeira oportunidade?

Para os garotos, a primeira relação sexual acontece por imposiçóes sócio culturais que exigem do homem a prova de sua virilidade, sendo que ter várias parceiras faz parte de sua formação heterossexual. Isso lhe confere um status social de adulto ${ }^{4,12,13,14,16}$. Para os homens, o sexo é uma etapa exigida para a vida adulta, enquanto para elas a sociedade cobra a abstinência antes do matrimônio ${ }^{13,16}$. Percebe-se que a sociedade, e até mesmo a família, induz comportamentos diferentes para homens e mulheres ${ }^{4}$.

Essa diferença de comportamento entre os gêneros é um espelho das influências culturais pelo qual a sociedade está regida. Homens e mulheres são conduzidos a iniciar o sexo por motivos diferentes, e esse fato se perpetua na prática das relaçóes sexuais. O homem é estimulado a praticar o sexo com diferentes parceiras no intuito de mostrar e provar sua heterossexualidade e faz parte da sua autoafirmação. Às mulheres é ensinado protelar a sexarca e manter a vida sexual monogâmica, com parceiro estável ${ }^{1}$.

Os adolescentes que já haviam iniciado a atividade sexual disseram receber uma educação mais permissiva dos pais ${ }^{12}$, inclusive entre as meninas ${ }^{6}$. Segundo a literatura $^{18}$, os pais contribuem com a perpetuação do machismo quando permitem que os meninos mantenham relaçóes sexuais antes do casamento ${ }^{12}$.

A liberdade sexual dada aos garotos pode ser evidenciada em um estudo qualitativo questionando a visão masculina sobre as mulheres. Foram entrevistados alguns adolescentes entre 15 e 18 anos residentes em Fortaleza $^{1}$, que afirmaram ser dotados de inteligência superior a das garotas e que a eles o sexo é permitido independente da relaçáo afetiva com o outro, gozam de privilégios como a liberdade sexual e delegam a elas a responsabilidade quanto ao uso de contraceptivos ${ }^{14}$. Entretanto, os próprios garotos afirmam que as meninas não podem adotar condutas táo liberais, que a elas o sexo deve ser restrito ${ }^{1}$.

\section{Influências dos fatores culturais}

Alguns estudos ${ }^{6,8,11,15,16}$ apontam que ter religião tem repercutido de maneira a postergar a idade da sexarca. Os jovens que afirmaram possuir religião adiaram o início da atividade sexual. Entretanto, a falta de religião parece ser mais comum entre os meninos ${ }^{6}$. Um estudo qualitativo realizado na cidade de Recife com adolescentes pertencentes a grupo religioso corrobora com estes achados. Esse estudo evidenciou que esses adolescentes veem o sexo antes do casamento como uma transgressão. Nesse grupo, o "ficar" representa a atitude de uma sociedade autônoma, egoísta e que valoriza apenas o próprio desejo ${ }^{19}$.

Se de um lado a condenação moral e religiosa ao sexo antes do matrimônio ainda seja um discurso presente, a mídia trata a gravidez antes do casamento como uma coisa natural, o que pode comprometer a tomada de decisão entre os jovens. Os rapazes têm que provar sua masculinidade precocemente, com o início muitas vezes prematuro da atividade sexual por pressão social ${ }^{20}$, e das moças, principais alvos de comprometimento de decisão, são cobradas atitudes castas.

A constituição familiar é fator relevante para o comportamento dos jovens. Um dos estudos sugere que o comportamento liberal das mães aumenta as chances do início precoce da vida sexual dos filhos, se comparadas às chances de filhos de mães menos liberais. Neste sentido, a supervisão do pai náo se mostrou significante em relaçáo ao comportamento sexual dos adolescentes 9 . O início sexual se deu mais cedo quando os adolescentes tinham pais separados ${ }^{16}$, não moravam com os pais ${ }^{15}$ ou quando moravam com apenas um deles ${ }^{6}$. Os adolescentes que afirmaram receber uma educação menos rígida iniciaram a prática sexual precocemente. A pouca escolaridade dos pais foi encarada como fator preditor para sexarca, assim como a falta de diálogo na família ${ }^{12}$.

Estar presente na vida dos filhos e saber onde estão e o que estão fazendo é importante para que haja interação para que a troca de informaçôes entre pais e filhos seja facilitada. Falar sobre sexo parece náo ser tarefa fácil: um estudo mostra que os pais têm vergonha de falar sobre o tema com os filhos ${ }^{18}$. Além disso, nas famílias monoparentais (em que um dos pais é o único responsável pela educação dos filhos e mantenedor do lar), esse membro da família tende a trabalhar mais horas e a deixar o jovem mais tempo sem supervisão?. 
O ambiente onde o adolescente vive $e^{1,11}$, a presença dos pais ${ }^{4}$ e o comportamento dos amigos ${ }^{6,12,14}$ têm grande influência na idade de início da atividade sexual. O comportamento sexual de um indivíduo está relacionado tanto à etapa de desenvolvimento em que se encontra quanto ao contexto familiar e social em que vive ${ }^{20}$.

A pressão dos pares inicia-se antes da relação sexual, visto que alguns adolescentes confirmaram já ter mantido alguma relação afetiva (namorado ou ficado), mesmo sem ter vontade ${ }^{6}$. Para garotos e garotas, estar namorando ou já ter tido namorado esteve associado ao início da atividade sexual ${ }^{9,13}$. Para ambos, ter amizade com outros adolescentes que iniciaram a prática sexual precocemente ${ }^{6,12,14}$, assim como ter irmáo ou irmã que engravidou fora de uma relação conjugal ${ }^{12}$, apresentou um maior risco de iniciar essa prática na adolescência.

O início sexual de fato é estimulado por pares, entre outros motivos pelo comportamento das pessoas com quem convivem e moram ${ }^{11}$. Os estudos mostraram que é importante conhecer os fatores individuais que influenciam o comportamento sexual dos adolescentes, mas algumas pesquisas têm se voltado para varáveis contextuais, inserindo a comunidade, e confirmam que esta variável deve ser melhor elucidada ${ }^{1}$.

O nível educacional dos adolescentes foi um dos resultados mais interessante deste estudo, pois independente de ser homem ou mulher, aqueles que não estavam inseridos em uma instituição de ensino formal apresentaram menor idade para sexarca ${ }^{6}$. Observa-se que à medida que o adolescente tem mais anos de estudo, posterga a sexarca $a^{6,8,9,11,12,16}$. Além disso, alguns estudos revelaram que o uso de anticoncepcionais é maior no grupo que tem maior escolaridade, e há menor risco de gravidez indesejada ${ }^{11}$. Manter-se estudando e ter bom relacionamento com os amigos e com os professores, além de ser fator protetor para o início precoce da atividade sexual leva a condutas mais saudáveis em relaçáo ao sexo, como por exemplo menor número de parceiros e uso de preservativo ${ }^{11}$.

De maneira geral, os adolescentes demonstraram pouco conhecimento sobre métodos anticoncepcionais e sobre as mudanças fisiológicas naturais da adolescência ${ }^{13}$. Embora algumas garotas tenham revelado procurar as mães quando surgem as dúvidas, os garotos afirmaram procurar os amigos ${ }^{13}$. Além disso, a precocidade da atividade sexual está possivelmente associada ao maior número de parceiros no futuro, o que gera um maior risco de IST e sexo desprotegido $0^{4,14,15}$.

Esta pesquisa apresentou algumas limitaçóes, que podem ter interferido em algumas interpretaçôes, especificamente nas questôes referentes à idade de ocorrência da sexarca, às relaçóes homossexuais, ao conceito de relaçáo sexual e à religiáo como fator de postergação da sexarca.

Em relação à idade, infelizmente algumas pesquisas abordaram a idade através das médias ou medianas, o que foi uma limitação para esta revisão, posto que as médias e medianas escondem os extremos e são justamente os adolescentes que se encontram em maior vulnerabilidade ${ }^{4}$. É de grande importância conhecer a idade mínima para o início sexual, visto que é com bases nesses dados que as medidas de saúde pública podem ser melhor planejadas, incluindo a população mais jovem nos programas sobre o tema.

Apenas um dos estudos citou relaçóes homossexuais $^{4}$, deixando uma lacuna a respeito dos fatores que permeiam o início da atividade sexual nesse grupo, como cita um dos artigos ${ }^{14}$. Essas são informações de grande importância na decisão das condutas promotoras de saúde.Além disso, os artigos não conceituaram relação sexual, e a ausência de padronização no uso do termo "atividade sexual" reforçou o que para alguns adolescentes pode significar apenas relações em que houve coito. É importante que seja feita essa abordagem com maior atençấo, permitindo ao adolescente reconhecer que atividade sexual não esta limitada ao coito e que outras práticas sexuais, como o sexo oral e anal, também merecem cuidados e orientaçóes.A dificuldade em estudar a temática "sexo em adolescentes" também deve ser considerada uma limitação, pois os jovens podem se sentir coagidos, mesmo sendo a participaçáa espontânea, ou participar com informaçóes que não sejam verdadeiras. Como citou um dos estudos ${ }^{15}$, meninos podem mentir a idade de iniciação sexual para provar a masculinidade, inclusive o maior número de parceiras, enquanto as meninas podem mentir por medo, vergonha e tabus ${ }^{15}$. Esse fato pode ter ocorrido mesmo com garantia do caráter sigiloso das pesquisas. Diante disso, entende-se que abordar os jovens sobre comportamento sexual não é uma tarefa fácil.

Outro fator estudado foi a religião, sendo citada nos artigos como um fator que adiou a sexarca. A fim de minimizar tal dificuldade, sugerem-se outros estudos com adolescentes que considerem o tipo de religião e o tempo dedicado às atividades religiosas, pois podem levar a resultados diferentes.

Algumas variáveis que foram citadas em apenas um artigo podem ser mais elucidadas, como por exemplo o uso de tabaco, álcool, drogas ilícitas, porte de arma nos últimos 12 meses e local de moradia, que foram fatores positivos para o início da atividade sexual ${ }^{16}$. Outro artigo referiu que as pessoas que moram nas grandes cidades têm maior risco para o sexo na adolescência do que as que moram na zona rural ${ }^{1}$. 
Outra variável que merece ser mais investigada, como afirma um dos artigos ${ }^{9}$, diz respeito à comunicação entre pais e filhos e a maneira como ela repercute no comportamento sexual.

\section{Conclusão}

Para estes estudos, o comportamento sexual está ligado a múltiplos fatores: individuais, religiosos, familiares, socioeconômicos, às relaçôes de namoro, escolaridade, e às questôes culturais, principalmente diferenças de gênero e influência dos pares, entre outros menos citados.

Muitos são os fatores que cercam o início da atividade sexual. Este estudo não tem a intenção de promover ou adiar a sexarca, mas de contextualizá-la e de identificar a faixa etária em que ela ocorre, além dos eventos que tornam os adolescentes mais vulneráveis.

Essa revisão demonstrou que meninos e meninas adotam comportamento sexual de risco. Além disso, a falta de escolaridade, o desconhecimento da proteção contra ISTs, o desconhecimento dos métodos contraceptivos, a falta de diálogo com os pais e a influência dos pares devem ser aspectos considerados no planejamento das ações de prevenção e educaçáo sexual, a fim de diminuir a vulnerabilidade a que os adolescentes estão expostos nesse período da vida.

É fundamental que o sexo seja discutido dentro da própria família e que os pais reconheçam a importância do seu papel na formação desses jovens. Os profissionais que tratam dessa temática também precisam trabalhar a prevenção do comportamento de risco, lembrando que manter um bom relacionamento com os adolescentes é importante para que se sintam mais confortáveis e permitam o diálogo e a orientação.

\section{Referências}

1. Silva KLD, Dias FLA, Maia CC, Pereira DCR, Vieira NFC, Pinheiro PNDC. A influência das crenças e valores culturais no comportamento sexual dos adolescentes do sexo masculino. Rev Enferm. 2010;18(2):247-52.

2. Davim RMB, Germano RM, Menezes RMV, Carlos DJD. Adolescente/adolescência: revisão teórica sobre uma fase crítica da vida. Rev Rene. 2009;10(2):131-40.

3. World Health Organization. Young people's health - a challenge for society. Technical report series 731. Geneva: WHO; 1986.

4. Gonçalves H, Béhague DP, Gigante DP, Minten GC, Horta BL, Victora CG, Barros FC. Determinants of early sexual initiation in the Pelotas birth cohort from 1982 to 2004-5, Southern Brazil. Rev Saúde Públ. 2008;42:34-41.

5. Trajano MFC, Quirino GS, Araújo GAG. Consequências da maternidade na adolescência. Cogitare Enferm. 2012;17(3):430-6.

6. Bergamim MD, Borges ALV. Fatores associados à iniciaçáo sexual entre adolescentes da zona oeste do município de São Paulo. Rev Gaúcha Enferm. 2009;30(3):420-8.

7. Heilborn ML, Aquino EML, Bozon M, Knauth DR. O aprendizado da sexualidade: reprodução e trajetórias sociais de jovens brasileiros. Rio de Janeiro: Fiocruz; 2006.

8. Paiva V, Calazans G, Venturi G, Dias R. Idade e uso de preservativo na iniciação sexual de adolescentes brasileiros. Rev Saúde Públ. 2008;42(1):45-53.

9. Borges AV, Schor N. Início da vida sexual na adolescência e relaçóes de gênero: um estudo transversal em São Paulo, Brasil, 2002. Cad Saúde Públ. 2005;21(2):499-507.

10. Leite IDC, Rodrigues RDN, Fonseca MDC. Fatores associados com o comportamento sexual e reprodutivo entre adolescentes das regióes Sudeste e Nordeste do Brasil. Cad Saúde Públ. 2004;20(2):474-81.

11. Borges, ALV. Pressão social do grupo de pares na iniciação sexual de adolescentes. Rev Esc Enferm. 2007;41(Esp):782-6.

12. Borges, ALV. Relações de gênero e iniciação sexual de mulheres adolescentes. Rev Esc Enferm. 2007;41(4):597-604.

13. Pelloso SM, Carvalho MDDB, Higarashi IH. Sexualidade e gênero: um estudo com adolescentes em um município de pequeno porte do Noroeste do Paraná. Acta Scientiarum Health Science. 2008;30(2):113-9.

14. Gubert D, Madureira VSF. Iniciação sexual de homens adolescentes. Ciên Saúde Colet. 2008;13(2):2247-56.

15. Cruzeiro ALS, Souza LDDM, Silva RAD, Horta BL, Muenzer RM, Faria AD, Pinheiro RT. Iniciação sexual entre adolescentes de Pelotas, Rio Grande do Sul. Rev Bras Crescimento Desenvolv Hum. 2008;18(2):116-25.

16. Hugo TDDO, Maier VT, Jansen K, Rodrigues CEG, Cruzeiro ALS, Ores LDC, Souza LDDM. Factors associated with age at first intercourse: a population-based study. Cad Saúde Públ. 2011;27(11),2207-14.

17. Teixeira AMFB, Knauth DR, Fachel JMG, Leal AF. Adolescentes e uso de preservativos: as escolhas dos jovens de três capitais brasileiras na iniciação e na última relação sexual. Cad Saúde Públ. 2006;22(7):1385-96.

18. Moreira MRC, Santos JFFQ. Entre a modernidade e a tradição: a iniciação sexual de adolescentes piauienses universitárias. Esc Anna Nery. 2011;15(3):558-66.

19. Paz FMA. Religiáo e sexualidade: permanências e transformaçóes da perspectiva de jovens pentecostais de Recife/PEBrasil. Ciên Sociais e Religiāo. 2012;13(15):83-113.

20. Gomes CM. Vivência em grupo: sexualidade, gênero, adolescência e espaço escolar. Rev APS. 2013;16(1):103-11. 